\title{
The impact of Covid-19 on education equity: A view from Barbados and Jamaica
}

\author{
Stacey N. J. Blackman ${ }^{1}$ (D)
}

Accepted: 27 June 2021 / Published online: 23 August 2021

(C) UNESCO IBE 2021

\begin{abstract}
The outbreak of Covid-19 worldwide has presented an unprecedented challenge for the equity-in-education agenda, especially in developing countries of the Global South (e.g., the English-speaking Caribbean). This article examines the impact school closures have had in Jamaica and Barbados, and highlights the emerging disparities the global pandemic has had on education. The central organizing questions are as follows: Who was affected by school closures in Barbados and Jamaica? How did the Ministries of Education (MOEs) support curriculum and instruction during the pandemic? What challenges does Covid-19 present for MOEs? What are the implications for education after Covid-19? School closure data suggest a gender disparity, with more males than females out of school due to Covid-19 from preprimary to secondary school in Barbados and Jamaica. MOEs in the region responded to school closures primarily by increasing access to technology to facilitate remote learning. Some of the challenges with continuing education for students during Covid-19 were due to a lack of infrastructure and amenities to support remote learning. Implications for education post-Covid-19 are considered.
\end{abstract}

Keywords Covid-19 $\cdot$ Caribbean education $\cdot$ Jamaica $\cdot$ Barbados $\cdot$ School closure $\cdot$ Equity in education

The outbreak of Covid-19 worldwide has presented an unprecedented challenge for the equity-in-education agenda, especially in developing countries of the Global South, such as the English-speaking Caribbean. The Education 2030 framework for action was proposed in Incheon, Korea, on May 21, 2015, at the World Education Forum. It was adopted 6 months later, on November 4, 2015. Some 184 UNESCO member states agreed to a more ambitious timetable to achieve inclusive, equitable quality education and to promote

Stacey N. J. Blackman

Stacey.blackman@cavehill.uwi.edu

1 School of Education, University of the West Indies Cave Hill, Cave Hill Road, Wanstead BB11000, Barbados 
lifelong learning opportunities for all by 2030. In the 2030 agenda, inclusive education maintains a prominent focus and is defined simply as "a process that helps overcome barriers limiting the presence, participation and achievement of learners" (UNESCO 2017, p. 13). While this definition has not changed fundamentally from UNESCO's (2005) iteration of inclusion at the international level, definitions remain contested and diffuse.

Debates about whether inclusion is understood as a process (UNESCO 2017), educational reform (Ainscow 1999), concept (Crockett and Kauffman 1998), or approach to education provision for children with disabilities (Ainscow 1999) remain unresolved. By contrast, there seems to be broader agreement internationally that education must be equitable, and this is defined by UNESCO (2017) as ensuring that the education of all learners is viewed as equally important. Within the context of the English-speaking Caribbean, Blackman et al. (2019) recognized the Caribbean's commitment to providing equitable inclusive education through statements in various educational acts that stressed universal access to schooling and the repudiation of discrimination toward the most vulnerable students in these contexts.

In the early months of the pandemic, UNESCO estimated that at least 1.3 billion children and youth were out of school and that school closures occurred in at least 138 countries (UNESCO Institute for Statistics 2020). School closures in the Caribbean affected at least 1.7 million children across 21 countries. According to Giannini (2020), the combination of school closures and confinement was expected to be most severe for those who are marginalized and vulnerable, including girls, students with disabilities, and those living in poverty.

The facts just presented provide a definite challenge for the Education 2030 agenda in light of the current pandemic affecting access to education across the world. Education 2030 replaced the previously unfinished Education for All (EFA) frameworks and Millennium Development Goals agendas, which failed to achieve inclusion by 2015. Interestingly enough, the 2030 framework for action does consider the impact of crises such as global pandemics on education. It recognizes that crises such as pandemics, wars, and natural disasters can harm a country's ability to recover postcrisis and also negatively affect education. It notes that entire generations can be left "traumatised, uneducated and unprepared to contribute to the economic and social recovery of their country or region. A crisis is a major barrier to access to education, stalling and in some cases reversing progress towards EFA in the last decade" (UNESCO 2015, p. 34). Given the level of unpreparedness of many school systems around the world during this pandemic, it is clear that the warning expressed in the Education 2030 agenda went unheeded by many governments. Countries were urged to create educational systems that are more resilient and prepared for crises in education, such as pandemics. In addition, they were encouraged to adopt the guidelines developed by the INEE (2010) as minimum standards for planning and response, which recommended strengthening the capacity of governments and civil society for disaster risk reduction and building coordination at the national, regional, and global levels to construct better, safer school systems that are more equitable after crises. For small island developing states, such as those in the Caribbean, two critical challenges to building more resilient and better prepared educational systems are finances and the availability of technical expertise in disaster risk management.

A corollary is that countries around the world will need to assess the possible impact of school disruption on inclusion and learning. Research, for example, by Burgess and Sievertsen (2020) argued that the Covid-19 pandemic affects all aspects of education, including instruction, assessment, and curriculum. Of significant concern is the loss of instruction time, which results in a phenomenon called learning loss. These authors cited research 
from Lavy (2012), who argued that reduced teaching hours caused significant differences in test score outcomes between students in different countries. It is estimated that a loss of 3 to 4 hours of instruction per week in mathematics for 12 weeks might be similar in magnitude to the loss of 1 hour of instruction per week for 30 weeks, a total loss of $6 \%$ of a standard deviation (Burgess and Sievertsen 2020, para. 4).

Countries within the Caribbean are some of the most vulnerable to the impact of Covid19 on both health and education. Not only could education loss result in higher attrition and retention rates for vulnerable students, but long term it could also result in a reduction in economic participation and in even higher rates of unemployment among youth. A similar view is that "extended school closures may not only cause loss of learning in the short term but also diminish human capital and economic opportunities for children and youth over the long term" (d'Orville 2020, p. 11).

This point made by d'Orville (2020) is borne out in an International Development Bank (IDB) study conducted during the first 6 months of the Covid-19 outbreak over the 2 weeks between April 16 and April 30, 2020. The research assessed the socioeconomic impact of the pandemic across 12,500 households in the Bahamas, Barbados, Jamaica, Suriname, Trinidad and Tobago, and Guyana (Beuermann et al. 2020). The findings of the survey revealed that the impact was quite severe, especially for families at the lower socioeconomic levels in these islands. The number of vulnerable households doubled within the first 2 weeks of the pandemic. The report stated further that the percentage of households working below minimum wage increased from 23\% in January 2020 to $43 \%$ in April 2020. A significant rise in unemployment and decline in the standard of living also occurred among those families. Another startling but not surprising statistic is that vulnerable households found it even harder to meet their basic needs, with $36.9 \%$ of these households experiencing dietary changes and hunger due to a lack of food security.

Employment opportunities were also adversely affected, with those from lower income and vulnerable groups experiencing higher levels of layoffs. Beuermann et al. (2020) argued that in January, households that earned below the minimum wage in tourismdependent countries recorded a higher percentage of layoffs from the workforce. They noted, "Tourism dependent countries approximately double the rate of job losses for both the highest and lowest brackets of the income distribution" (para. 5). Not only do these trends suggest a rise in income inequality, but they also indicate that disadvantage would extend to education. Access to technology, which is the primary modality used to continue education during the Covid-19 pandemic, would not be available to students living in the most vulnerable households.

The preceding findings support information about the widening gap between students with and without access to technology and educational resources, based on the 2018 Programme for International Student Assessment (PISA) data (OECD 2019). Although now dated, these data provide a useful point of analysis to extrapolate from and understand the likely impact of gaps in access to learning resources, given Covid-19 conditions. Jaramillo's (2020) report utilized a composite analysis of PISA data (OECD 2019) for the Caribbean and Latin America that examined the role of socioeconomic status and of access to and ownership of technology for adolescents 15 years and older. When socioeconomic status was considered, students from the highest quintile were 5.5 times more likely to have access to a tablet or computer than were their counterparts from the poorest quintile. Jaramillo's research further suggested that differences in ownership were exceptionally unequal, with those from the highest quintiles eight times more likely than peers from the poorest quintiles to own a computer device or tablet. Moreover, Jaramillo argued that internet coverage and access via mobile devices was "on average no higher than $55 \%$ in 
any country in the region" (p. 9). It can therefore be argued that both Beuermann et al.'s (2020) and Jaramillo's research support a growing thesis of educational inequality for the most vulnerable students as a result of Covid-19 conditions.

This conceptual paper examines the impact of school closures and highlights the emerging disparities that the global pandemic has emphasized for students and the educational system in Jamaica and Barbados. Next, a comparative analysis of the responses of the MOEs in Jamaica and Barbados is considered, with a focus on the nature and types of supports implemented during the period of school closure. The paper then discusses the challenges and implications of the Covid-19 pandemic on education on the two islands. The central organizing questions are as follows: Who was affected by school closures in Barbados and Jamaica? How did the MOEs support curriculum and instruction during the global pandemic? What challenges does Covid-19 present for MOEs, and what are the implications for education after Covid-19?

\section{Mapping the terrain on school closures for school-age students in Barbados and Jamaica}

Who has been affected by school closures in Barbados and Jamaica? UNESCO estimated that the impact of school closures due to the Covid-19 pandemic was most severe in seven Caribbean islands: Jamaica, Barbados, Belize, Grenada, Guyana, Suriname, and the Republic of Trinidad and Tobago. These same islands were identified by Beuermann et al. (2020) as the hardest hit economically during the pandemic. Table 1 documents the number of out-of-school students affected by pandemic-related school closures for each country, up to the tertiary level.

School closure data suggest a gender disparity, with more males than females being out of school due to Covid-19, from preprimary to secondary school, in Barbados and Jamaica. Statistics in Table 1 indicate that in Jamaica, 552,125 school-age students up to the secondary school level were affected by Covid-19 school closures. Of these, 270,941 were females and 281,678 were males. At the primary school level, the largest number of students affected were males $(129,184)$, whereas 119,652 female students were affected by school closures. This pattern was repeated at the preprimary level, with males accounting for 51,642 and females for 51,578 of learners out of school. At the secondary level, boys accounted for 100,852 students and girls for 99,711 students of the out-of-school population due to Covid-19.

Table 1. Number of students out of school due to Covid-19 school closures in the worst affected Caribbean Islands, by gender

\begin{tabular}{lcc}
\hline & Males & Females \\
\hline Jamaica & 309,568 & 317,588 \\
Barbados & 26,822 & 30,708 \\
Belize & 53,690 & 54,201 \\
Grenada & 17,461 & 17,827 \\
Guyana & 109,039 & 109,112 \\
Suriname & 76,750 & 72,684 \\
Trinidad and Tobago & 141,747 & 141,320 \\
\hline
\end{tabular}

Numbers include up to the tertiary level of schooling. Data from UNESCO Institute for Statistics (2020). 
These figures can be juxtaposed to those for the island of Barbados, which had 45,109 school-age learners who were affected by school closures. Of this number, 22,120 were female and 22,989 were male. At the preprimary level, 2,644 females and 2,676 males were out of school due to Covid-19 in 2020. At the primary school level, 20,218 learners were out of school, with the majority being boys (10,448 boys and 9,770 girls). Secondary school closures in Barbados affected 19,571 learners, with a small majority of those being males (9,865 boys and 9,706 girls; UNESCO Institute for Statistics 2020).

The data from both Barbados and Jamaica suggest that more boys than girls are potentially at greater risk for poor academic outcomes due to school closures. The situation is further compounded for some families on the larger island of Jamaica, given its economic status, geography, and levels of poverty. Boys from rural and remote primary and secondary schools in Jamaica are particularly at risk of further educational loss and declines in achievement. Lewin (2020) argued that school closure statistics should not be conflated with those from the global out-of-school initiative. Lewin stated, "Children not attending school as a result of school closures by government should not be confused with conventionally defined out of school children. Their casualties are unrelated, and the numbers affected are vastly different" (p. 21). He went on to note that these students remain at risk as a result of global school closures and still have a need to learn and be included in education.

What also remains missing from school closure data is the numbers of school-age children with disabilities who have been affected by Covid-19 in the Caribbean. These would include those who are in special schools, special education units, and resource rooms. Moreover, how the intersections of gender, poverty, and disability act to disadvantage these students has not been well documented within available data sources. We now turn our attention to the responses of MOEs in the region, in particular in Barbados and Jamaica, to examine what procedures they adopted to keep education on track during national lockdowns.

\section{Comparison of Barbados's and Jamaica's Ministry of Education responses to Covid-19}

This comparative analysis examines how MOEs for the islands of Jamaica and Barbados responded to school closures as a result of the worldwide Covid-19 pandemic. It is imperative, however, to first understand the educational context of each island. Jamaica is one of the largest islands in the Caribbean, with a landmass of $10,990 \mathrm{~km}^{2}$, located just south of Cuba. According to statistics posted on the United Nations' data website, as of 2019, Jamaica had a population of 2,948,000. The island's now-dated educational sector plan, entitled Vision 2030 (Ministry of Education, Youth and Information 2009), noted that the MOE assumes responsibility for education through its head office and six regional offices across the island. Although formal education remains mainly controlled by the MOE, education is also available through private purveyors in Jamaica.

Jamaica's educational system consists of four levels: early childhood, primary, secondary, and tertiary. Schools are organized by grades, with Grade 0 catering to those from kindergarten to infant school, Grades 1 through 9 for those categorized as primary (all age or primary and junior), and Grades 7 through 13 designated as high school. Jamaica also has independent preparatory and high schools that cater to students from Grades 1 through 13. In Jamaica, trained teachers who are university 
graduates account for $65.0 \%$ of the teaching complement in schools. Figures from the Education Statistics of 2018-2019 also suggest that 21.4\% of teachers are trained college graduates, with smaller percentages in the untrained category. Untrained tertiarylevel graduates (trained at teachers' colleges) account for $1.5 \%$ of teachers, $3.8 \%$ of teachers are untrained secondary school graduates, and $7.3 \%$ are untrained university graduates.

By contrast, Barbados is one of the smallest islands in the Caribbean, occupying 430 $\mathrm{km}^{2}$ just east of the Windward Islands. The population of Barbados, according to the United Nations Statistical Division's (2019) World Statistics Pocketbook, stands at 285,000. The structure of the educational system mirrors that of Jamaica with respect to tiers of education; however, differences are noticeable in that Barbados does not have a graded system of educational classification. Students in Barbados complete 2 years of preprimary education from ages 3 to 4 as nursery and reception students. They then advance to primary school for 6 years, from Infants A (5 years old) to Class 4 (10 years old). This is then followed by 5 years of compulsory secondary education for students between the ages of 11 and 15 from Forms 1 to 5. Postsecondary but nontertiary education occurs in Lower 6 and Upper 6 Form. It lasts for a period of 2 years, until students matriculate into tertiary-level education, starting around age 18. Another difference between Jamaica and Barbados is that special education in Barbados falls under the ambit of the MOE rather than private purveyors, as is the case on the larger island.

Data on teacher training in Barbados are neither current nor disaggregated, as is the case for Jamaica, but a cursory glance does suggest that the majority of public primary school teachers are trained (202) as opposed to untrained (118); similarly, at the secondary school level, 987 teachers are trained and 333 are reported as untrained (Ministry of Education 2016).

\section{Supporting curriculum and instruction during school closures}

MOEs in the region responded to school closures and the continuation of the curriculum primarily via increased access to technology to facilitate remote learning. This approach mirrors that of many international jurisdictions as an interim strategy to continue education during the Covid-19 pandemic. However, a key question of concern is whether access to more technology translated into greater inclusion and quality education during online learning. It seems intuitive to argue that the pandemic at least provided the Caribbean with an opportunity to further the international equity and inclusive education agenda through addressing access to education via technology. But has it? Much of the information on how the MOEs in the Caribbean approached and managed the pandemic is still evolving since March 2020, when school closures occurred worldwide.

Researchers in this area must understand that information is not always easy to find because the decisions made are not always officially documented. The Covid-19 crisis placed educational systems in a state of flux, and therefore access to information was dependent on how technologically advanced, organized, and transparent MOEs' websites were for each Caribbean island. It is likely that educators would need to rely on information gathered from other secondary sources, such as local newspapers, authorized government information websites, official newsletters, and video conferences convened by MOEs. 


\section{Access to technology}

Barbados announced its first two cases of Covid-19 on March 17, 2020; this was swiftly followed by school closures on March 18, 2020. The MOE's policy on curriculum and pedagogy dictated an immediate move to a synchronous format of teaching and learning wherein students would continue to receive their education online (Rudder 2020). One implication of this move was that teachers needed to be upskilled in preparation for delivering sessions. A trainer-of-the-trainers model was implemented, and information technology coordinators across all schools received further training before being tasked with building the capacity of other teachers at their respective institutions. Rudder noted that besides sharing best practices, a major focus of this training was on changing the instructional design used by teachers, especially the presentation of information for online learning.

It was reported that a G-Suite for Education devices drive was pursued in collaboration with corporate Barbados, Barbadians from the Diaspora, and the Ministry of Finance to expand access to technology for all children (Loop News Barbados 2020, para. 2). However, some 4,000 children identified as vulnerable had no access to technology. They could not continue their learning remotely because priority was given to children sitting for the Caribbean Secondary Entrance Examination (CSEC) and Caribbean Examination Council Certificates (para. 4). The implication is that many children were disadvantaged, which raises questions about inclusivity and whether we value the learning of all students equitably.

The decision to close schools nationally in Jamaica occurred on March 12, 2020, and the Ministry of Youth and Information mandated a switch to remote teaching and homeschooling. School closures in Jamaica followed the announcement of the first 12 confirmed Covid-19 cases, between March 10 and 16, 2020. Like Barbados, Jamaica's MOE placed its emphasis on helping students and teachers access technology to facilitate homeschooling. School closures were subsequently extended until April 21, then May 31, and finally September 6, 2020 (Ministry of Education, Youth and Information 2020c, para. 1).

Very similar to the Barbadian experience, in Jamaica, access to technology was provided via private-public partnerships. The Jamaican MOE (Ministry of Education, Youth and Information 2020a, para. 1) noted that E-Learning Jamaica was instrumental in distributing 40,000 Samsung tablets. These tablets were shared between the six education regions across the island under the Tablet in Infant and Primary School Project. To facilitate teachers and students in rural Jamaica, it was reported that E-Learning partnered with local post offices to distribute 25,000 tablets to principals and registered teachers; 10,000 were sourced from Royal Computer Limited and 15,000 from Productive Business Solutions. It was estimated that these tablets cost approximately US\$800 million (2020d, paras. 6, 10).

\section{Access to resources and support}

MOEs in Barbados and Jamaica pursued an inclusive agenda concerning making learning resources available via their websites. Resources and support provided by the MOEs can be classified as those that facilitated teaching and learning, those that were infrastructural and provided internet access, and those that supported parents. 


\section{Supporting teaching and learning}

In Jamaica's case, the MOE reported in its newsletter (2020c, para. 3) that teaching and learning would be supported through the establishment of the School's Not Out Programme. This program provided televised lessons that aired during the week from 9:00 a.m. to 12:00 noon and Saturdays from 9:30 a.m. until 1:00 p.m. The lessons were designed to widen access, especially for those students in rural areas who might not have had access to a computer, laptop, or the internet. Several curriculum resources were also posted on the MOE's website for Caribbean Advanced Proficiency Examination (CAPE), (CSEC), and City Guild's students. These were accompanied by live online lessons or sessions made available through the One on One Learning Management System for students in Grades 1 to 13 (2020c, para. 3). For students at the secondary level of schooling, this system served the following functions:

1. It allowed teachers to create virtual classes and add students to the online platform.

2. It provided a way for students' study skills to be assessed, and a national report was generated to guide the development of revision workshops for students.

3. It allowed teachers to teach their students synchronously for 40 minutes.

4. It provided access to ready-made question banks to help teachers design quizzes and engage in formative assessment based on CSEC and CAPE syllabi (2020g, para. 1).

For teachers in Barbados, Google's G-Suite was used in a similar manner, with the MOE reporting that 3,000 teachers had been trained to use this learning management platform (Loop News Barbados 2020, para. 4).

The Jamaican MOE (2020b) posted helpful websites for teachers and students that included Book Fusion, Edu-Focal, CHEETA, and DropBox, which provided useful information and content to promote teaching and learning. In addition, printing services were also made available in each region to support the preparation of learning kits for students (para. 1).

\section{Supporting internet access}

Internet access was supported through private-public partnerships in Barbados and Jamaica. To illustrate, in Jamaica, ReadyTV provided internet access to 238 schools. At the same time, the Ministry of Education, Youth and Information ensured that 100 schools had internet access in the parishes of Kingston, Manchester, St. James, and Trelawny (2020d, para. 2). In addition to this roving internet, hotspots were set up in the six education regions to facilitate emergency remote teaching. In Barbados, more than 35,000 students and 250 teachers benefited from free internet access (Rudder 2020).

Moreover, telecom provider Digicel assisted MOEs in Barbados and Jamaica with internet access through the provision of data plans. Data plans were subsidized and also zero rated for frequently used platforms and websites, such as Google. Zero-rated websites accessed by students and teachers in Jamaica included yammer.com, mymbcc. edu.jm, and google.com. Similarly, those in Barbados accessed e-learning platforms, Google Classroom, and Google Meet (Ministry of Education, Youth and Information 2020b, para.1). 


\section{Supporting parents}

Parental support during the Covid-19 pandemic was also a key concern of MOEs in both Barbados and Jamaica, and partnerships between ministries were used to assist parents during the pandemic. In Jamaica, for example, the Honourable Nigel Clarke, Minister of Finance, noted in a budget debate the expansion of a social protection net for the most vulnerable through the addition of JAM $\$ 347$ million (US\$2,335,985) for feeding children at the early childhood level. This amount boosted the total allocation for school feeding to JAM\$5.1 billion (US\$34,287,861.00; Linton 2019, para. 3). Moreover, the Ministry of Labour and Social Security provided cash grants payable to parents in May and June 2020 through the Programme for Advancement Through Health and Education (PATH). It was noted further (Campbell 2020) that "Government's Covid-19 Allocation of Resources for Employees (CARE Programme) targeted vulnerable parents who struggled to finance their children's education. Expenses covered by the programme included the cost of books, uniforms and other supplies" (para. 1).

In both Barbados and Jamaica, the MOEs also established hotlines to provide psychological, teaching, and counseling support for all students, teachers, and parents. Services offered for both islands were for those who experienced difficulty coping with the emotional and psychological impact of social isolation, and specifically for parents who had additional homeschooling responsibilities or for students who needed academic assistance.

\section{Delayed or postponed high-stakes assessments}

National assessments at the early childhood, primary, and secondary levels in Barbados and Jamaica were postponed due to Covid-19. In Barbados, the Barbados Secondary School Entrance Examination, also known as the 11+, was rescheduled for 3,300 primary school students until July (Rollock 2020, para. 1). To assist in their preparation for the examination, however, the MOE announced that primary schools would recommence classes for 4th-form students on Monday, June 15, 2020. This gave teachers 4 weeks' contact time to prepare students for the examination (para. 2). By contrast, in Jamaica, the Ministry of Education, Youth and Information (2020f) reported that the results of the Primary Exit Profile examination would be used to determine primary school students' placement at secondary school.

The Ministry of Education, Youth and Information (2020e) noted that in Jamaica, "instruction and assessment engagements during the emergency issues of quality negatively impacted remote teaching, equity and equality and thus these scores should not be used as final grades on the students' report cards" (para. 1). Promotion decisions were therefore made based on data gathered from several sources, including the students' scores for the current academic year, as assessed by project work, homework, class tests, and worksheets obtained up until March 13, 2020. In those cases where retention rather than promotion was the outcome, this decision was made by schools in collaboration with the parents, the child, and school administrators. The team would consult data from the child's current scores, previous scores from the student's academic profile, and the teacher's projected performance ratings (para. 1).

One point of difference to note is that Jamaica announced that 3 weeks of diagnostic assessment would take place from September 7 to 30, 2020, at the start of the next 
academic year. The assessments would determine the extent of learning loss and readiness for learning due to school closures (Ministry of Education, Youth and Information 2020f, para. 8). At the time of this writing, no similar measures had been announced for Barbados.

\section{Challenges for an inclusive educational system during the Covid-19 pandemic}

Despite the innovations already mentioned - and in some cases, adaptations that emerged during the pandemic - the challenges of providing inclusive and equitable opportunities for all students in Jamaica and Barbados were exacerbated by Covid-19. This section of the paper considers the following question: What challenges does the Covid-19 pandemic present for MOEs?

Preliminary data from the UNESCO Institute for Statistics suggest that boys are affected by school closures more than are girls. This is perhaps especially so for those who are in at-risk categories, such as students with disabilities and those from poor communities and rural areas in Jamaica that remained underserved during the MOEs' response to the pandemic. Some of the challenges with continuing education provision for these students during Covid-19 were due to a lack of infrastructure and amenities to support remote learning in both Barbados and Jamaica. In Barbados, it was estimated by the MOE that 4,000 vulnerable children from low-income homes and those with disabilities simply lacked access to the necessary technology to continue their learning online and at home (Loop News Barbados 2020, para. 4).

Another challenge the pandemic posed to the equity and inclusion agenda is that emergency homeschooling is likely to affect children from lower-income households disproportionately, with higher rates of education loss. Lewin (2020) argued that the inequalities in education highlighted by the Covid-19 pandemic need to be reduced, including the "extreme variations in the capacity of households to home-school children" (p. 19). This speaks to parents' capacity to provide children with the necessary technology to study. It also brings into sharp focus parents' levels of education and their influence on the assistance they can provide to their children at the primary and secondary levels of schooling. Parents with no or low levels of qualification and certification are not likely to be in a position to assist their children with schoolwork. Moreover, they are also less likely to take on the responsibility of teaching their children at home. Over time, this could result in even more significant educational losses for their children due to school closures. For students from poorer communities and those with impairments, in both Barbados and Jamaica, this is double jeopardy, as the intersections of poverty, low socioeconomic status, and impairment serve to further exclude these children from participating in online learning.

\section{Implications of the Covid-19 pandemic for Caribbean education}

What are the implications for education (and in particular, for inclusive education) going forward after the Covid-19 pandemic in the Caribbean (and in particular, for islands such as Jamaica and Barbados)? At this time, it seems optimistic to be speaking about postCovid conditions of education, given the protracted spread of the virus worldwide. It is perhaps more appropriate to frame this section of the argument as how education must evolve and adapt to Covid conditions. This last section of the paper considers possible 
pathways forward for education in Jamaica and Barbados, with a critical focus on areas of concern raised throughout this discourse.

\section{Gender and education}

Covid-19 has magnified educational inequality among males and females in both Barbados and Jamaica. These educational disparities between the numbers of boys affected by school closures, as compared with the numbers of girls, mean there is a need to consider whether education loss for boys is potentially even more significant (Arnove 2020). Any investigation, however, should consider Bailey and Charles's (2020) gender differential framework, which examines structural factors that have an impact on the educational performance of Caribbean males and females. Although it is too early to measure the extent of that loss, of immediate concern is how schools and teachers prioritize interventions for boys. Teachers need to examine boys' online learning experiences and the salience of the curriculum for meeting their educational needs. According to research by Zhao (2012, 2018a, 2018b, 2020), the Covid-19 pandemic provides an opportunity for schools to examine how their curriculum can be reimagined to suit the interests and needs of students. He argued that "not all students need or are interested in the same curriculum" (p. 31). It is time to examine "what" and "how" boys learn rather than to stick to prescribed and predetermined content that is of little relevance and interest to these students in Caribbean schools.

Educational loss must be avoided if boys and girls are to go on to have successful careers and be included socially in society post-Covid-19 (d'Orville 2020). Given the out-of-school statistics from UNESCO in Table 1, which show that more boys than girls were affected by school closures, it is tempting to suggest that Covid-19 conditions lend credence to the male marginalization thesis espoused by past academics, such as Miller (1994), in Jamaica. Miller's argument suggested, among other things, that boys were more likely than their female cohorts to start school later, attend irregularly, drop out more often, and have lower rates of completion of schooling and achievement. However, one must be aware of the arguments made by researchers such as Bailey and Charles (2010), who suggested that the performance of males is on par with that of females in the arts, sciences, business, and humanities at both the secondary and tertiary levels of education. They further argued that gender was not sufficiently predictive of performance among Caribbean boys and girls. According to these researchers, structural factors such as school type, socioeconomic status, administration of the school, school location, school curriculum, and type of school attended prior to entry into secondary school were more predictive of the differences in performance between males and females. The effects of the Covid-19 pandemic on school-age children in both Barbados and Jamaica are yet to be understood. Still, it seems fair to argue that educational equality and quality are priorities that MOEs must address if boys and girls from the most vulnerable households are to be fully included and achieve success, as indicated by SDG 4 Education 2030 goals.

\section{Curriculum and instruction considerations}

The research thus far suggests that MOEs in both Barbados and Jamaica transitioned curriculum and instruction fairly successfully to online modalities only for those able to access and benefit from it. Access to technology and educational resources were also crucial to 
the success of online and homeschooling initiatives instituted by MOEs during school closures. The shift to online learning was abrupt for schools, teachers, students, and parents, and adapting to this new reality required agility.

However, as one examines the possible implications for curriculum and instruction in Barbados and Jamaica, it is difficult to argue that the Covid-19 pandemic did not present new opportunities for teachers and schools to part with old, didactic ways of delivering the curriculum (Arnove 2020; Zhao 2020). An argument made by Zhao (2018a) is that schools can experiment with personalized and paced learning. Personalized learning will offer students a choice of curriculum content, levels of difficulty and mastery, and immediate feedback, that could augur well for boys and vulnerable groups of students, such as those with disabilities. Digital textbooks and media (Chabbott and Sinclair 2020), along with interactive slide presentations, can take students on a journey through the material with as little or much guidance as required from teachers, with students firmly in control of their learning. However, a caution is in order: With more emphasis being placed on access to technology, a new digital divide is looming, with students from vulnerable groups unable to access laptops, tablets, and the internet to accrue any benefits (d'Orville 2020).

Although not yet part of the curriculum, it is necessary that Caribbean schools also develop modules on and about global pandemics. Topics might include the history of global pandemics; developing psychosocial resilience; maintaining a positive mindset and relationships during social isolation; the impact of pandemics on society, community, and culture; and influence on the economy, governance, health, family, school, and community.

For parents, the Covid-19 pandemic reinforced the importance of parental involvement in their children's learning in the delivery of curriculum and instruction. Parents in both Jamaica and Barbados experienced "the flipped classroom", as many of them became their children's teachers during school closures. Although it is unrealistic to expect parents to approximate what trained teachers do in classrooms, it does challenge the maxim that schools and teachers need to be the primary place and persons responsible for students' learning. This point was also made by Zhao (2020), who noted that Covid-19 had caused us to rethink where learning takes place: "When schools were closed, and the students were home, learning took place. Students took online courses and interacted with others online" (p. 32). While this seems to suggest that hybrid approaches to schooling are possible, one point of concern remains: the question of the quality of instruction parents provided during school closures. What children learned during school closures varied significantly across socioeconomic levels and will even influence the extent of educational loss experienced post-Covid. This combination of both social and educational inequality will be felt more acutely in lower income households in Jamaica and Barbados. As noted by Arnove (2020),

The individuals most marginalised and discriminated against have suffered the most by school closures and the efforts to reach students with online instruction. Delivery of education this way illustrates the difficulties posed for students who lack computers or who live in remote areas without electricity or WIFI. (p. 43)

Another group of students who are of concern are those with disabilities. It is important of concern is those with disabilities. It is important to determine how school closures affected their access to their curriculum, instruction, services, and therapies. To date, much of the information available from MOEs in the Caribbean has not captured the procedures for continuing education of children with disabilities. Online learning can be "Janus headed" for these students, meaning that it can simultaneously translate into greater participation in learning because technology offers that capability. On the other hand, it can also result in further exclusion, depending on teachers' knowledge of how to use technology to 
adequately accommodate students' remote learning. Other considerations include the level of flexibility built into the type of curriculum used, communication, and engagement with students during synchronous instruction. Similarly, returning to school after the Covid-19 pandemic is also fraught with potential exclusions, as children with coexisting conditions and impairments are more likely to stay home rather than return to traditional classrooms. What we do know is that school closures are expected to magnify the risks of disadvantage, social isolation, and reduced peer interaction for students with disabilities.

Amidst these sobering assessments of the impact of Covid-19 conditions on students' learning is another layered reality that presents the positive impact technology can have on teaching and learning. Many teachers have had to adapt their teaching to the online environment and learn how to engage their students, using online platforms, the internet, and television resources as part of the curriculum. Broadly speaking, the utilization of technology during the Covid-19 pandemic has expanded access to technology for some vulnerable students who previously would not have had access to it due to their families' socioeconomic status. Other benefits accrued, according to research by Vargo et al. (2020), are that the expansion of technology has increased schools' capacity to continue learning at a safe distance, deliver synchronous online instruction, and innovate in pedagogy to support learning.

\section{Education policy and planning}

All of the factors mentioned have implications for education policy and planning on the islands of Barbados and Jamaica. Given the grim economic outlook forecasted by the IDB study by Beuermann et al. (2020), it is clear that MOEs in Jamaica and Barbados must set new priorities that capitalize on many of the private-public and intergovernmental partnerships that were forged during the Covid-19 pandemic. D'Orville (2020) speculated that investments in education might be reduced as countries around the world adjust to new post-Covid realities. This seems likely for both Barbados and Jamaica, which are heavily dependent on the tourism sector, which was hit hardest during this global pandemic. The knock-on effect is that education for vulnerable students will be negatively affected. As d'Orville (2020) argued,

Globally school closures disproportionately hurt vulnerable and disadvantaged students who rely on schools for a range of social services, including health and nutrition.... But, their impact on education is likely to be most devastating in countries with already low learning outcomes, high dropout rates and low resilience to shocks. (p. 12)

This statement adequately captures the situation on the ground in both Barbados and Jamaica economically and educationally. The goals for educational planners and policy makers in Jamaica and Barbados must be to reinvent education so it presents a more balanced response at the levels of gender, inclusion, and equity in education as it moves forward amidst Covid-19 conditions. It demands further that educational policy makers; parents; teachers; students; and school, community, and business leaders understand that they are all part of a fragile ecosystem that is dependent on the collaboration and partnerships so quickly formed during these pandemic conditions. It is only through support for and leveraging of the strengths of each of these systems that education will recover from the shocks delivered by the Covid-19 pandemic. 


\section{References}

Ainscow, M. (1999). Understanding the development of inclusive schools. Falmer Press.

Arnove, R. (2020). Imagining what education can be post-COVID-19. Prospects, 49, 43-46. https://doi. org/10.1007/s11125-020-09474-1.

Bailey, B., \& Charles, S. (2010). Gender differentials in Caribbean education systems. Commonwealth Education Partnerships, 70-72. https://www.cedol.org/wp-content/uploads/2012/02/70-72-2010. pdf

Beuermann, D. W., Álvarez, L. G., Hoffman, B., \& Vera-Cossio, D. (2020, May 14). COVID-19, The Caribbean crisis. Caribbean Dev-Trends. https://blogs.iadb.org/caribbean-dev-trends/en/covid-19the-caribbean-crisis/

Blackman, S. N., Conrad, D. A., \& Brown, L. I. (2019). Achieving inclusive education in the Caribbean and beyond. Springer.

Burgess, S., \& Sievertsen, H. H. (2020, April 1). School, skills and learning: The impact of COVID-19 on education. VOXEU CERP. https://voxeu.org/article/impact-covid-19-education

Campbell, E. (2020, June 12). Back to school bailouts for poor parents. The Gleaner. http://jamaicagleaner.com/article/lead-stories/20200612/back-school-bailout-poor-parents

Chabbott, C., \& Sinclair, M. (2020). SDG 4 and the COVID-19 emergency: Textbooks, tutoring, and teachers. Prospects, 49, 51-57. https://doi.org/10.1007/s11125-020-09485-y

Crockett, J. B., \& Kauffman, J. M. (1998). Taking inclusion back to its roots. Educational Leadership, $56(2), 74-77$.

d'Orville, H. (2020). COVID-19 causes unprecedented educational disruption: Is there a road towards a new normal? Prospects, 49, 11-15. https://doi.org/10.1007/s11125-020-09475-0

Giannini, S. (2020, March 25). Three ways to plan for equity during the coronavirus school closures. World Education Blog. https://gemreportunesco.wordpress.com/2020/03/25/three-ways-to-plan-forequity-during-the-coronavirus-school-closures/

INEE [Inter-agency Network for Education in Emergency] (2010). INEE minimum standards for education: Preparedness, response, recovery. https://inee.org/resources/inee-minimum-standards

Jaramillo, S. G. (2020). COVID-19 and primary and secondary education: The impact of the crisis and public policy implications for Latin America and the Caribbean. United Nations Development Programme. https://www.latinamerica.undp.org/content/rblac/en/home/library/crisis_prevention_and_ recovery/COVID-19-y-educacion-primaria-y-secundaria--repercusiones-de-la-.html

Lavy, V. (2012). Do differences in schools' instruction time explain international achievement gaps? Evidence from developed and developing countries. National Bureau of Economic Research. https://www.nber.org/papers/w16227.pdf

Lewin, K. M. (2020). Contingent reflections on coronavirus and priorities for educational planning and development. Prospects, 49, 17-24. https://doi.org/10.1007/s11125-020-09480-3

Linton, L. (2019). Government increases support for students under PATH. Jamaica Information Service. https://jis.gov.jm/govt-increases-support-for-students-under-path/

Loop News Barbados (2020). Ministry embarks on tech drive to equip students during COVID19 times. https://barbados.loopnews.com/content/ministry-embarks-tech-drive-equip-stude nts-during-covid-19-times

Miller, E. (1994). Marginalization of the Black male. Canoe.

Ministry of Education, Science, Technology and Innovation (2016). Statistics on education in Barbados at a glance. https://mes.gov.bb/Download.ashx?file=Attachments\%2F2015-2016+STATISTICS+ $\mathrm{ON}+\mathrm{EDUCATION}+\mathrm{IN}+\mathrm{BARBADOS}+\mathrm{AT}+\mathrm{A}+$ GLANCE$\cdot$ pdf \&name=2015-2016+STATISTICS+ $\mathrm{ON}+\mathrm{EDUCATION}+\mathrm{IN}+\mathrm{BARBADOS}+\mathrm{AT}+\mathrm{A}+\mathrm{GLANCE}$

Ministry of Education, Youth and Information (2009). Vision 2030 Jamaica national development plan: Education draft section plan. https://planipolis.iiep.unesco.org/sites/default/files/ressources/jamai ca_vision_2030_education_sector_plan.pdf

Ministry of Education, Youth and Information (2019). Jamaica school's profile 2018-2019. Statistics Section Planning and Development Division, Ministry of Education, Youth and Information.

Ministry of Education, Youth and Information (2020a). 65,000 tablets being procured for schools, teachers. https://moey.gov.jm/65000-tablets-being-procured-schools-teachers

Ministry of Education, Youth and Information (2020b). Access to zero-rated websites: Additional institutions. https://moey.gov.jm/access-zero-rated-websites-\%E2\%80\%93-additional-institutions

Ministry of Education, Youth and Information (2020c). Extension of school closure for the academic year 2019/2020. https://moey.gov.jm/extension-school-closure-academic-year-20192020

Ministry of Education, Youth and Information (2020d). Postal service to help deliver tablets for teachers. https://moey.gov.jm/postal-service-help-deliver-tablets-teachers-1 
Ministry of Education, Youth and Information (2020e). Progression of students at early childhood, primary and secondary levels. https://moey.gov.jm/progression-students-early-childhood-primary-and-secon dary-levels-0

Ministry of Education, Youth and Information (2020f). Schools reopen for CSEC and CAPE students June 08. https://moey.gov.jm/schools-reopen-csec-and-cape-students-june-8

Ministry of Education, Youth and Information $(2020 \mathrm{~g})$. One on one online refresher classes to support CSEC and CAPE students. https://moey.gov.jm/one-one-online-refresher-classes-support-csec-capestudents

OECD (2019). PISA 2018 results (Volume II): Where all students can succeed. https://www.oecd-ilibrary. org/sites/b5fd1b8f-en/index.html?itemId=/content/publication/b5fd1b8f-en

Rollock, M. (2020, May 16). 11-plus exam date set: Phased reopening of schools. Barbados Government Information Service. https://gisbarbados.gov.bb/blog/common-entrance-date-set-phased-reopening-ofschools/

Rudder, R. (2020). Supporting teachers and education personnel to ensure continuity of learning in the Caribbean Caribbean webinar \#1. UNESCO. https://en.unesco.org/fieldoffice/santiago/events/webin ar-1-Caribbean-teachers

UNESCO (2005). Guidelines for inclusion: Ensuring access to education for all. https://unesdoc.unesco. org/ark:/48223/pf0000140224

UNESCO (2015). Education 2030 Incheon declaration and framework for action. http://www.unesco.org/ new/fileadmin/MULTIMEDIA/HQ/ED/ED_new/pdf/FFA-ENG-27Oct15.pdf

UNESCO (2017). A guide for ensuring inclusion and equity in education. https://unesdoc.unesco.org/ark:/ 48223/pf0000248254

UNESCO Institute for Statistics (2020). Education: From disruption to recovery. https://en.unesco.org/ covid19/educationresponse

United Nations Statistical Division (2019). World statistics pocketbook.. https://unstats.un.org/unsd/publi cations/pocketbook/files/world-stats-pocketbook-2019.pdf

Vargo, D., Zhu, L., Benwell, B., \& Yan, Z. (2020). Digital technology use during COVID-19 pandemic: A rapid review. Human Behavior and Emerging Technologies, 3(1), 13-24. https://doi.org/10.1002/hbe2. 242

Zhao, Y. (2012). World class learners: Educating creative and entrepreneurial students. Corwin.

Zhao, Y. (2018). Reach for greatness: Personalizable education for all children. Corwin.

Zhao, Y. (2018a). Personalizable education for greatness. Kappa Delta Phi Record, 54(3), 109-115. https:// doi.org/10.1080/00228958.2018.1481645

Zhao, Y. (2020). COVID-19 as a catalyst for educational change. Prospects, 49, 29-33. https://doi.org/10. 1007/s11125-020-09477-y

Publisher's Note Springer Nature remains neutral with regard to jurisdictional claims in published maps and institutional affiliations.

Stacey Blackman is a senior lecturer in special and inclusive education at the University of the West Indies Cave Hill campus. She completed her first and second degrees at the University of the West Indies, and her PhD at Cambridge University (UK), as a Cambridge Commonwealth Scholar. She was also a past deputy dean of the Faculty of Humanities and Education at the University of the West Indies, Cave Hill. She is a fellow of the Cambridge Commonwealth Trust and member of many professional organizations, such as the American Education Research Association (AERA), the Council for Exceptional Children (CEC), and the British Psychological Association. Her research addresses a broad range of topics and activities on teachers' pedagogical practices, inclusion, pupil perspectives, and wider issues related to persons with disabilities in the Caribbean region. 